CURVELO, C. R. S.; FERNANDES, E. F.; DINIZ, L. H. B.; PEREIRA, A. I. A. Desempenho agronômico da couve-flor (Brassica oleracea var. botrytis) em função da adubação silicatada. Revista de Agricultura Neotropical, Cassilândia-MS, v. 6, n. 1, p. 87/91, jan./mar. 2019. ISSN 23586303.

\title{
Desempenho agronômico da couve-flor (Brassica oleracea var. botrytis) em função da adubação silicatada
}

\section{Carmen Rosa da Silva Curvelo ${ }^{1}$, Érika Faleiro Fernandes ${ }^{1}$, Layane Hyasmin Bernardes Diniz $^{1}$, Alexandre Igor de Azevedo Pereira ${ }^{1}$}

${ }^{1}$ Instituto Federal Goiano, Campus Urutaí, Urutaí, Goiás, Brasil. E-mail: carmencurvelo@ yahoo.com.br, erika_faleirofernandes@hotmail.com, layane_hyasmin@hotmail.com, aiapereira@yahoo.com.br

Recebido: 26/03/2018; Aceito: 13/11/2018.

\section{RESUMO}

A couve-flor (Brassica oleracea var botrytis) está entre as hortaliças mais cultivadas e consumidas no Brasil, sendo uma das principais brássicas cultivadas. Dessa forma, objetivou-se avaliar os efeitos da adubação silicatada na qualidade e rendimento pós-colheita da couve-flor cultivar Sharon. O delineamento experimental adotado foi em blocos casualizados (DBC), com quatro tratamentos e sete repetições. Foram utilizadas oito mudas por parcela, com o critério de plantio uniformidade de tamanho. Os tratamentos corresponderam às seguintes doses de silício: $0 \mathrm{mg} \mathrm{L}^{-1}$ (T1), 20,0 $\mathrm{mg} \mathrm{L}^{-1}$ (T2), 30,0 mg L $\mathrm{m}^{-1}$ (T3) e 40,0 $\mathrm{mg} \mathrm{L}^{-1}$ (T4). Os parâmetros avaliados foram: número de folhas $(\mathrm{NF})$, comprimento e diâmetro do caule $(\mathrm{cm})$, diâmetro da inflorescência $(\mathrm{cm})$, massa da matéria fresca da couve-flor completa $(\mathrm{kg})$, massa da matéria fresca da inflorescência $(\mathrm{kg})$ e aparência da couve-flor através de uma escala de notas, que variavam de 1 a 5, aos 4, 9, 14, 19, 24 e 29 dias após a colheita. Os resultados obtidos indicaram que não houve influência do silício no desempenho agronômico da couve-flor; no entanto, pode-se observar uma melhoria na qualidade pós-colheita da couve-flor provinda da adubação silicatada via foliar, justificando a sua utilização e a realização de estudos posteriores.

Palavras-chave: silício, hortaliças, pulverização foliar, produtividade.

\section{Agronomic performance and post-harvest quality of cauliflower as a function of silicate fertilization}

\begin{abstract}
Cauliflower (Brassica oleracea var botrytis) is among the most cultivated and consumed vegetables in Brazil, being one of the main cultivated brassicas. The objective of this work was to evaluate the effects of silica fertilization on the quality and post-harvest yield of the Sharon cauliflower. The experimental design was completely randomized (DIC), with four treatments and seven replicates. Eight seedlings per plot were used, with the criterion of planting uniformity of size. The treatments applied corresponded to the following doses of silicon:

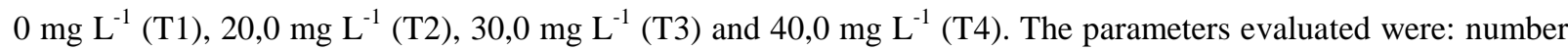
of leaves $(\mathrm{LN})$, stem length and diameter $(\mathrm{cm})$, inflorescence diameter $(\mathrm{cm})$, complete cauliflower weighing $(\mathrm{kg})$, inflorescence weighing $(\mathrm{kg})$ and post harvest quality of cauliflower through a scale of notes, ranging from 1 to 5; 4, 9, 14, 19, 24 e 29 days after harvest. The results indicate that there was no influence of the silicon on the agronomic performance of cauliflower, however, an improvement in the post-harvest quality of cauliflower can be observed from silica fertilization via leaf, justifying its use and the accomplishment studies.
\end{abstract}

Keywords: silicon, vegetables, foliar spraying, productivity. 
A produção de hortaliças é uma atividade que ocupa lugar de destaque na economia brasileira. Atualmente, é crescente a adoção de sistemas alternativos como plantio direto, cultivo mínimo e orgânico na produção de hortaliças, pois a busca dos consumidores por produtos cultivados de forma sustentável, em uma produção adequada quanto às questões sociais e ambientais, tem afetado significativamente a forma de cultivo e comercialização dessas hortaliças (Almeida et al., 2007).

No momento atual da agricultura, vem se buscando novas formas de cultivo que apresentem custos reduzidos na implantação das lavouras e que causem poucos danos ao meio ambiente e ao solo, com um manejo conservacionista, e que o uso de insumos, como fertilizantes e agrotóxicos, seja mais racional e o menor possível (Valarini et al., 2011).

Dentre as hortaliças mais cultivadas e consumidas encontra-se a couve-flor (Brassica oleracea var botrytis), uma das principais brássicas cultivadas no Brasil, principalmente entre os agricultores familiares, por ser uma cultura lucrativa e bastante exigente em mão-de-obra, sobretudo na fase de colheita (May et al., 2007). No entanto, o sucesso de seu cultivo depende de vários fatores, como a escolha do cultivar adaptado às condições edafoclimáticas da região de cultivo. O cultivar Sharon tem-se mostrado promissor para cultivo no Cerrado, com produtividade atingindo 30,6 t ha-1 (Júnior et al., 2012). Outro fator determinante para se alcançar altas produtividades é o manejo adequado da adubação, podendo enfatizar e potencializar os métodos de utilização da adubação orgânica e mineral (Valarini et al., 2011). Sob o ponto de vista nutricional, essa hortaliça é rica em minerais como cálcio e fósforo, contém quantidades apreciáveis de vitamina $\mathrm{C}$, livre de gorduras e colesterol e com teores baixos de sódio e calorias (May et al., 2007).

A inclusão do silício como fertilizante agrícola ainda é uma prática pouco usual na horticultura, devido ao fato de o mesmo não ser considerado um nutriente essencial, porém, seus benefícios têm sido cada vez mais reconhecidos por pesquisadores do mundo todo (Ludwig et al., 2015).

A couve-flor é uma hortaliça de difícil conservação pós-colheita à temperatura ambiente, devido à transpiração e ao processo respiratório intenso, o que acarreta alteração na coloração da inflorescência (Souza et al., 2010).

Existem alguns trabalhos científicos sobre a conservação da inflorescência da couve-flor. Segundo May et al. (2007), a embalagem em filme plástico (polietileno ou PVC) perfurado diminui a perda de água e aumenta a durabilidade do produto devido à redução da respiração. A comercialização no varejo de inflorescência de couve-flor em balcões refrigerados e/ou armazenados a baixas temperaturas (entre 0 a $5^{\circ} \mathrm{C}$ ) e alta umidade relativa ( 85 a $98 \%$ de UR) se torna uma das técnicas mais eficientes para aumentar sua durabilidade (Filgueira, 2008; Almeida et al., 2007).

No entanto, ainda são escassas informações sobre a utilização do silício na cultura da couve-flor. Diante disso, objetivou-se avaliar os efeitos da adubação silicatada via foliar no rendimento e na qualidade póscolheita da couve-flor em horta comercial no município de Urutaí - GO.

O experimento foi conduzido no município de Urutaí - Goiás, no período de outubro de 2016 a janeiro de 2017, em um produtor local que atende a demanda do município, cujas coordenadas geográficas são $17^{\circ} 29^{\prime} 10^{\prime \prime} \mathrm{S}$ de latitude e $48^{\circ} 12^{\prime} 38^{\prime}$ " O de longitude, a $697 \mathrm{~m}$ de altitude. O clima da região é classificado como tropical com inverno seco e verão chuvoso, do tipo Cwb pela classificação de Köppen. A temperatura média anual é de $23^{\circ} \mathrm{C}$ no período de setembro a outubro, podendo chegar até a máxima de $30^{\circ} \mathrm{C}$ e, entre os meses de junho e julho, com mínima inferior a $15^{\circ} \mathrm{C}$. A precipitação média anual é de 1000 a 1500 mm, com umidade relativa média do ar de $71 \%$.

O solo da área experimental foi classificado como Latossolo Vermelho Amarelo Distrófico, de textura argilosa (Embrapa, 2013). Os resultados obtidos na análise química, segundo metodologia de Raij et al. (2001), na camada de $0-20 \mathrm{~cm}$ de profundidade antes da

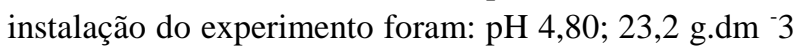
de M.O (Matéria Orgânica); 6,1\% de CTC; saturação por bases de 42,3\%; 6,7 mg.dm ${ }^{-3}$ de P; 3,50 $\mathrm{cmol}_{\mathrm{c}} \cdot \mathrm{dm}^{-3}$ de $\mathrm{H}+\mathrm{Al} ; 0,2 \mathrm{cmol}_{\mathrm{c}} \cdot \mathrm{dm}^{-3} \mathrm{de} \mathrm{Al}^{3+} ; 0,37 \mathrm{cmol}_{\mathrm{c}} \cdot \mathrm{dm}^{-3}$ de K ; $1,70 \mathrm{cmol}_{\mathrm{c}} \cdot \mathrm{dm}^{-3} \mathrm{de} \mathrm{Ca}^{2+}$ e $0,50 \mathrm{cmol}_{\mathrm{c}} \cdot \mathrm{dm}^{-3} \mathrm{de} \mathrm{Mg}^{2+}$.

$\mathrm{O}$ delineamento experimental adotado foi em blocos ao acaso (DBC), com quatro tratamentos e sete repetições, sendo cada parcela com dimensões de 3,0 $\mathrm{x}$ $2,0 \mathrm{~m}$.

As mudas de couve-flor (cv. Sharon) foram adquiridas em um viveiro comercial certificado da cidade vizinha Ipameri- $\mathrm{GO}$ e transplantadas em 01/10/2016, no espaçamento de $0,8 \mathrm{~m}$ entre linhas e $0,50 \mathrm{~m}$ entre plantas. Cada unidade experimental foi composta por 48 plantas, com oito plantas por linha de plantio, sendo utilizadas como parcela útil as quatro plantas centrais e o critério de uniformidade de tamanho das mudas. Os tratamentos corresponderam às seguintes doses: $0 \mathrm{mg} \mathrm{L}^{-1}$ (T1), 20,0 mg L $\mathrm{m}^{-1}$ (T2), 30,0 mg L $\mathrm{m}^{-1}$ (T3) e $40,0 \mathrm{mg} \mathrm{L}^{-1}$ (T4) de silicato de potássio, que foi a fonte de silício $(\mathrm{Si})$ utilizada, sendo diluído em um litro de água para ter uma melhor homogeneidade; posteriormente, foi depositado em uma bomba costal e complementado com água para 20 litros (L). Assim, foram feitas as aplicações via foliares, com o tempo de molhamento até o escorrimento do produto para promover uma distribuição homogênea nas plantas. As 
aplicações da adubação foliar foram realizadas aos 20 e 40 dias após o transplante (DAT). Toda a aplicação do adubo foliar foi efetuada mediante uso de pulverizador costal de $20 \mathrm{~L}$.

Devido ao fato de o pH do solo estar muito ácido, inicialmente foi feita a correção do solo com calcário dolomítico e uma adubação de plantio de acordo com as recomendações da análise de solo. O controle fitossanitário para pragas, doenças e plantas daninhas foi realizado sempre que necessário através do monitoramento diário, sendo eliminadas as plantas que apresentavam algum sintoma de doenças e pragas. Vale ressaltar que não foi utilizado nenhum produto químico específico para esse fim, utilizando-se capinas manuais para as plantas daninhas e irrigação por aspersão.

No presente trabalho, foi utilizado o cultivar de couve-flor Sharon, em função da sua adaptabilidade à região, apresentando inflorescência de granulação média, coloração branca e peso médio de 0,9 a $1,2 \mathrm{~kg}$, adaptado para o cultivo no fim da primavera/verão. Seu ciclo é de 90 a 100 dias (May et al., 2007).

As plantas foram colhidas aos 90 DAT e levadas para o setor de olericultura do campus Urutaí IFGoiano, onde passaram por uma prévia lavagem para retirada de todas as impurezas, sendo deixadas por cima de papel toalha para escorrer o excesso de água. As avaliações físicas foram realizadas no mesmo dia da colheita, acondicionando-se posteriormente as plantas em câmaras frias para as avaliações de pós-colheita.

Os parâmetros fítotécnicos avaliados foram: número de folhas (NF), comprimento e diâmetro do caule (CDC), diâmetro da inflorescência (DI), massa da matéria fresca da couve-flor completa (MFCC), massa da matéria fresca da inflorescência da couve-flor (MFIC) e produtividade (P).

Para obtenção do diâmetro e do comprimento foi utilizada fita métrica, com os resultados expressos em centímetros $(\mathrm{cm})$, ao passo que a pesagem foi realizada em balança digital da marca SEGMA (capacidade: 40 $\mathrm{kg}$, divisão: $5 \mathrm{G}$, corpo em plástico ABS injetado, prato inoxidável, display LCD com iluminação, display duplo (para vendedor e cliente), teclado 24 teclas, painel à prova de respingo, indicador de bateria baixa, indicador de bateria carregando, Bivolt (110v-220v), bateria recarregável), com os resultados em quilogramas $(\mathrm{kg})$.

A verificação da aparência da couve-flor foi realizada através da diagnose visual, ou seja, uma avaliação de aparência da mesma, e a conservação da inflorescência aos 4, 9, 14, 19, 24 e 29 dias após colheita em geladeira comum a $10 \pm 2^{\circ} \mathrm{C}$, utilizando-se uma escala de notas (nota $1=$ cabeças comerciais deterioradas; nota 2 = cabeças comerciais bem deterioradas; nota $3=$ cabeças comerciais moderadamente deterioradas; nota $4=$ cabeças comerciais levemente deterioradas e nota $5=$ cabeças comerciais sem deterioração), sendo utilizados três avaliadores e, assim, obtida a respectiva média das notas.

Os resultados foram analisados junto ao software estatístico SAEG. Os dados foram submetidos à análise de variância e, as médias, comparadas pelo Teste de Scott Knott ao nível de $5 \%$ de probabilidade. Os resultados, quando significativos, foram submetidos à análise de variância e de regressão em forma de gráficos, com análise de regressão polinomial (quadrática ou linear). Caso seja quadrática, os resultados devem ser discutidos por sua máxima eficiência (calculada a partir da derivação da equação). Quando não significativas, as variáveis podem ser demonstradas em gráficos (com o valor médio) ou em tabelas.

O comprimento do caule das couves-flores com diferentes doses do adubo silicatado não obteve diferença significativa. Quanto ao peso da couve-flor completa, observou-se que não houve diferença significativa entre os tratamentos 1 e 2, mas estes diferiram-se dos demais (T3 e T4). Já no peso da inflorescência, houve significância em quase todos os tratamentos, exceto no T1 (Tabela 1).

O número de folhas por planta variou de 15 (T2, T3) a 16 (T1, T4), com uma média de 15,5 folhas por planta, valor inferior ao encontrado por Kikuti e Filho (2007) para o cultivar Sharon, que foi de 20 folhas por planta.

Assim como no número de folhas, o tamanho do caule das plantas de couve-flor também não diferiu entre si. Nos tratamentos analisados quanto ao diâmetro, identificaram-se diferenças significativas tanto no caule, quanto na inflorescência (Tabela 1).

Todos os valores observados na Tabela 1 , com exceção do diâmetro do caule e das couves adquiridas comercialmente, ficaram abaixo dos obtidos por Júnior et al. (2012) para o cultivar Sharon.

Segundo Ferreira (1983), a temperatura é o principal fator a estimular a iniciação dos botões florais e o desenvolvimento das folhas de couve-flor, estando diretamente relacionada ao tamanho da cabeça. Isso sugere que tal caráter apresenta alta sensibilidade às mudanças ambientais, o que não permite generalizações quanto ao padrão de determinado cultivar para esse parâmetro. Além das condições ambientais contrastantes entre os locais, as diferenças encontradas na literatura podem estar relacionadas às diferentes épocas de realização dos experimentos, pois estações mais quentes favorecem o desenvolvimento da parte vegetativa da planta, com redução do diâmetro de cabeça e, consequente, da produção (May et al., 2007). 
Tabela 1. Paramêtros fitotécnicos do desempenho agronômico da couve-flor (Brassica oleracea var. botrytis) submetidas a diferentes doses de adubação silicatada. Câmpus Urutaí/IFGoiano, Urutaí - GO, 2017.

\begin{tabular}{ccccccc}
\hline Tratamento & $\begin{array}{c}\text { Cabeça } \\
\text { completa } \\
(\mathbf{k g})\end{array}$ & $\begin{array}{c}\text { Inflorescência } \\
(\mathbf{k g})\end{array}$ & $\begin{array}{c}\text { Comprimento do } \\
\text { caule } \\
(\mathbf{c m})\end{array}$ & $\begin{array}{c}\text { Número de folhas } \\
(\mathbf{N F})\end{array}$ & $\begin{array}{c}\text { Diâmetro } \\
\text { do caule } \\
(\mathbf{c m})\end{array}$ & $\begin{array}{c}\text { Diâmetro da } \\
\text { inflorescência } \\
(\mathbf{c m})\end{array}$ \\
\hline 1 & $1,610 \mathrm{a}$ & $0,750 \mathrm{a}$ & $29 \mathrm{a}$ & $16 \mathrm{a}$ & $5,0 \mathrm{a}$ & $21 \mathrm{a}$ \\
2 & $1,045 \mathrm{c}$ & $0,245 \mathrm{~d}$ & $29 \mathrm{a}$ & $15 \mathrm{a}$ & $4,6 \mathrm{~b}$ & $16 \mathrm{~b}$ \\
3 & $1,335 \mathrm{~b}$ & $0,275 \mathrm{~b} / \mathrm{c}$ & $30 \mathrm{a}$ & $15 \mathrm{a}$ & $4,6 \mathrm{~b}$ & $15 \mathrm{~b}$ \\
4 & $1,595 \mathrm{a}$ & $0,260 \mathrm{c}$ & $32 \mathrm{a}$ & $16 \mathrm{a}$ & $4,8 \mathrm{a}$ & $13 \mathrm{~b}$ \\
\hline
\end{tabular}

Médias seguidas da mesma letra minúscula na coluna não diferem entre si em uma média de $10 \%$. T1= $0 \mathrm{mg} \mathrm{L}^{-1}$ de silício; T2= 20 $\mathrm{mg} \mathrm{L}^{-1}$ de silício; $\mathrm{T} 3=30 \mathrm{mg} \mathrm{L}^{-1}$ de silício; $\mathrm{T} 4=40 \mathrm{mg} \mathrm{L}^{-1}$ de silício; T5= comercial.

No que diz respeito ao número de folhas da couveflor, Almeida et al. (2007) afirmam que normalmente está relacionado à maior ou menor precocidade de cada cultivar, sendo que os cultivares de ciclo mais longo tendem a formar um maior número de folhas do que aqueles mais precoces.

Em relação à avaliação da qualidade pós-colheita (Figura 1), os tratamentos 1 e 2 obtiveram os melhores resultados, seguidos pelos demais. É sabido que as práticas pós-colheita começam a ser influenciadas desde as condições de cultivo das hortaliças e que estas determinam o seu valor nutricional, a qualidade sanitária e as características organolépticas, o que, por sua vez, influenciam sua aceitabilidade e preferência pelo consumidor (Embrapa, 2010). A inflorescência deve ser firme, pesada e livre de danos causados por insetos e por manuseio inadequado (Moreira, 2010).

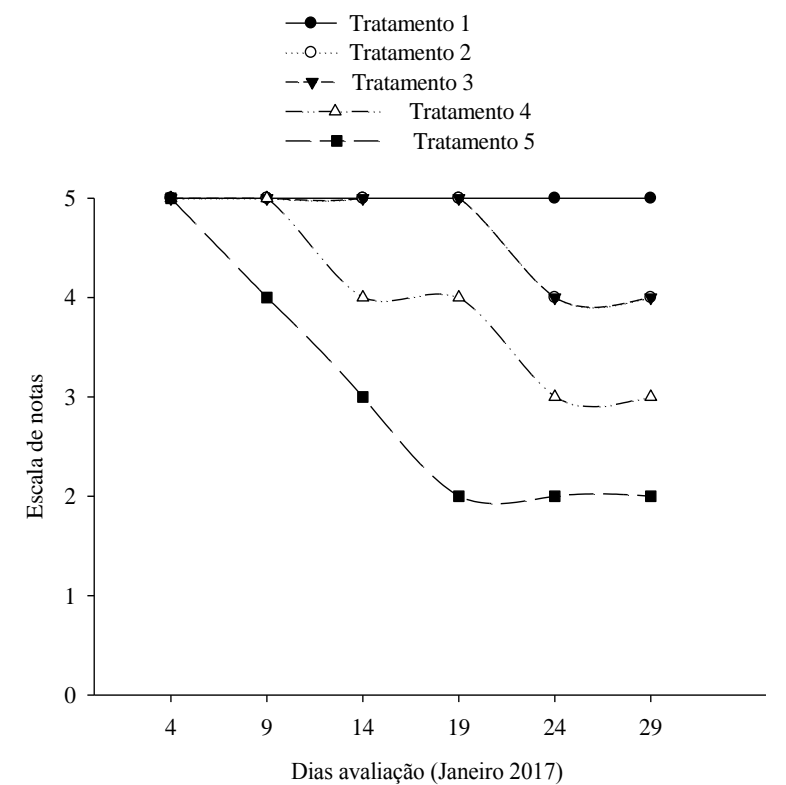

Figura 1. Avaliação da qualidade pós-colheita da couve-flor (Brassica oleracea var. botrytis) em cinco tempos (4, 9, 14, 19, 24 e 29 dias), utilizando-se escala de notas de 1 a 5 . Câmpus Urutaí/IFGoiano, Urutaí - GO, 2017.

Paulino et al. (2013), trabalhando com silicato de sódio como fonte de silício, observou maior produtividade e menor queima das brácteas na pós- colheita em Helicônia Golden Torch. O mesmo autor verificou que, utilizando doses de silício entre 0 e 1200 $\mathrm{kg} \mathrm{ha}^{-1}$, com as fontes, cimento, silicato de cálcio e silicato de sódio, é possível se ter diferenças nos aspectos produtivos e de pós-colheita.

Em síntese, as doses de silício via foliar não influenciaram significativamente as características fitotécnicas avaliadas entre os tratamentos. No entanto, a aparência da couve-flor tratada com o silício apresentou um melhor desempenho no final do período de armazenamento nos tempos avaliados. É notório, porém, que esse tema deve ser mais aprofundado em novos estudos, devido à sua escassez na literatura.

\section{Referências Bibliográficas}

Almeida, K., Carvalho, G.J., Gomes, L.A.A., Duarte, W.F., Fontanetti, A. 2007. Produção orgânica de couve-flor em sistema de plantio direto e convencional. Revista Brasileira de Agroecologia, 2, 1216-1219.

Embrapa. Empresa Brasileira de Pesquisa Agropecuária. 2010. Diagnóstico do manuseio pós-colheita de couve-flor e repolho em uma cooperativa de produtores de hortaliças em Planaltina. Brasília-DF.

Embrapa. Empresa Brasileira de Pesquisa Agropecuária. 2013. Sistema brasileiro de classificação dos solos. 3. ed. BrasíliaDF: Embrapa Solos.

Ferreira, F.A. 1983. Efeito do clima sobre as brássicas. Informe Agropecuário, 9, 12-14.

Filgueira, F.A.R. 2008. Novo manual de olericultura: agrotecnologia moderna na produção e comercialização de hortaliças. UFV.

Júnior, O.P.M., Cardoso, A.F., Leão, É.F., Peixoto, N. 2012. Desempenho de cultivares de couve-flor de verão em Ipameri. Ciência Rural, 42, 1923-1928.

Kikuti, A.L.P., Filho, J.M. 2007. Potencial fisiológico de sementes de couve-flor e desempenho das plantas em campo. Revista Brasileira de Sementes, 29, 107-113.

Ludwig, F., Mayer, R.H., Schmitz, J.A.K. 2015. Silício via foliar na produção e qualidade da cenoura. Revista Cultivando o Saber, 8, 373-383. 
May, A., Tivelli, S.W., Vargas, P.F., Samra, A.G., Sacconi, L. V., Pinheiro, M.Q. 2007. A cultura da couve-flor. CampinasSP: Instituto Agronômico-IAC. (Boletim Técnico IAC, n. 200).

Moreira, L.M. 2010. Diagnóstico do manuseio pós-colheita de couve-flor e repolho em uma cooperativa de produtores de hortaliças de Planaltina-DF. Brasília-DF: Embrapa Hortaliças.

Paulino, A.S., Albuquerque, A.W., Filho, G.M., Pereira, F.R.S. 2013. Helicônia "Golden Torch": produtividade e qualidade pós-colheita sob diferentes fontes e doses de silício. Revista Brasileira de Engenharia Agrícola e Ambiental. 17, 615-621.
Raij, B., Andrade, J.C., Cantarella, H., Quaggio, J.A. 2001 Análise química para avaliação da fertilidade de solos tropicais. Campinas-SP: Instituto Agronômico de Campinas.

Souza, A.M., Gioppo, M., Gonçalves, J., Ayub, R.A., Rezende, B.L.A., Otto, R.F. 2010. Caracterização pós-colheita de dois híbridos de couve-flor. Revista Biotemas, 23, 45-49.

Valarini, P.J., Oliveira, F.R.A., Schilickmann, S.F., Poppi, R.J. 2011. Qualidade do solo em sistemas de produção de hortaliças orgânico e convencional. Horticultura Brasileira 29, 485-490. 